\title{
Necrotizing Fascittis: Microbiological Characteristics And Predictors of Postoperative Outcome
}

\author{
A. Krieg ${ }^{1}$, A. Röhrborn ${ }^{1}$, J. Schulte am Esch ${ }^{2 n d}{ }_{1}$, D. Schubert ${ }^{2}$, L. W. Poll ${ }^{2}$, C. Ohmann ${ }^{3}$, S. Braunstein ${ }^{4}$, \\ W. T. Knoefel ${ }^{1}$ \\ ${ }^{1}$ Department of General Surgery, ${ }^{2}$ Institute of Diagnostic Radiology, ${ }^{3}$ Coordination Centre for Clinical Trials, ${ }^{4}$ Institute of Pathology, \\ Heinrich Heine University Duesseldorf, Germany
}

\begin{abstract}
Objective: Necrotizing fasciitis is a life threatening soft-tissue infection with a high morbidity and mortality. Prompt treatment based on extensive surgical debridement and antibiotic therapies are the therapeutic principles.

Methods: The medical records of patients with necrotizing fasciitis ( $\mathrm{n}=26$ ) from 1996 to 2005 were retrospectively analyzed.

Results: The localization of necrotizing fasciitis was most commonly the trunk (42.3\%). Type I polymicrobial infection was the dominating infection. The involvement of anaerobic bacteria was associated with an increase in the number of surgical revisions $(p=$ 0.005). Length of postoperative intensive care unit stay, duration of postoperative ventilation and mortality were significantly increased in the ASA IV-V group. Computed tomography displayed only a limited significance as diagnostic tool for initial diagnosis.

Conclusions: In severe cases the combination of necrotic skin and soft tissue gas facilitates the correct diagnosis, which should than be followed by immediate - and most often - repeated debridement. If anaerobes are isolated an early and aggressive second look is necessary.
\end{abstract}

Key words: Necrotizing fasciitis, soft tissue infection, ASA classification

\section{INTRODUCTION}

Necrotizing fasciitis is a rare but aggressive soft-tissue infection, which involves the fascial layers and the subcutaneous tissue, while skin and muscle initially remain intact [1]. This infection, which is usually induced by virulent, toxin producing bacteria, can occur in any region of the body but it is predominantly located in the abdominal wall, perineum and extremities $[2,3]$. On the basis of microbiological cultures Giuliano and colleagues [4] divided the necrotizing fasciitis into two distinct groups. Type I infections are polymicrobial and involve non-group-A streptococci, aerobes and/or facultative anaerobic bacteria. Type II is usually caused by $\beta$-haemolytic group-A streptococci alone or in combination with staphylococci. Predisposing factors of the disease are diabetes, alcohol and intravenous drug abuse as well as immunosuppression and peripheral vascular disease $[5,6]$. However, necrotizing fasciitis has also been reported in young and previously healthy individuals.

An early sign of necrotizing fasciitis is local erythema and pain out of proportion to findings of physical examination as well as fever. Skin necrosis due to thrombosis of blood vessels at the fascial level is a sequel of the initiating process and is often associated with severe sepsis [7-10]. Histomorphological hallmarks are necrosis of the superficial fascia with blood vessel thrombosis, severe inflammation of the dermis and subcutaneous fat as well as subcutaneous fat necrosis. Sometimes myonecrosis of underlying skeletal muscle is obvious [11-13]. Diagnostic clues include clinical findings and detection of soft-tissue gas or in less obvious cases edema and stranding of the fascial layers by computed tomography (CT) scanning as well as soft-tissue fluid by magnetic resonance imaging (MRI) [14-17].

Because of the high mortality ranging between 6 and $76 \%$ in different reports, prompt and aggressive therapy based on early and extensive surgical debridement, antibiotics and intensive care is necessary [7].

The aim of the present study was to analyze the factors affecting the outcome of patients with necrotizing fasciitis treated at our institution over the past 9 years. At the beginning of this time period a necrotizing fasciitis alertness "attitude" was instituted, presenting every dubious case to particularly involved staff surgeons.

\section{Material And Methods}

The medical results of patients who had been treated at our department for necrotizing fasciitis between 1996 and 2005 were analyzed retrospectively. The diagnosis of necrotizing fasciitis was established based on clinical findings such as characteristic skin changes, pain out of proportion to physical findings, fever, leucocytosis and elevated c-reactive protein levels as well as intraoperative findings such as necrosis of the superficial fascia and fat and the presence of foulsmelling fluid known as „dishwater pus“.

In 10 cases $(n=10)$ a CT scan was performed. CT examinations were reviewed separately and blinded by two radiologists. To assess the predictive value of CT, CT scans from 10 patients with other soft tissue infec- 
tions such as cellulitis and phlegmonia were included in the radiological review. All pathological changes were noted including those of the cutis, subcutis, fasiacl layers and muscle. In cases which remained unclear despite these examinations suspected foci were exposed surgically and the procedure was chosen according to the clinical aspect of the tissue. If the diagnosis was not adequately established by these methods, a biopsy specimen was analyzed by frozen section or rapid embedding process and measures were taken accordingly, e.g. a mild non mutilating debridement until verification of the diagnosis by histopathological examination. All cases included in this study finally had histopathological verification of the disease.

We assessed the value of the different diagnostic procedures performed in each case before radical debridement. We also reviewed the medical results for impact of demographic and clinical data as well as laboratory findings at the time of admission, comorbidities, site of infection, time from symptoms to admission, number and type of operations, the duration of hospitalization and the length of intensive care unit (ICU) stay as well as days on the respirator. The patients were classified by organisms isolated from swabs or tissue specimens during the first surgical treatment as type I and type II infections according to Giuliano and associates [4]. The physical status of the patients before the first surgical treatment was assessed according to the criteria of the American Society of Anaesthesiologists (ASA) [18].

Data analysis was performed using the SPSS 11.5 software package (SPSS Inc., Chicago, IL, USA). Correlation between epidemiological, clinical and microbiological variables was examined using the nonparametric Mann-Whitney-test. A two-tailed p-value less than 0.05 was considered to indicate statistical significance.

\section{RESULTS}

Twenty-six consecutive patients with necrotizing fasciitis were treated at our department between 1996 and 2005. Fifteen patients $(57.7 \%)$ were transferred to our department from other hospitals and seven patients $(26.9 \%)$ from other departments of our university. Only four patients $(15.4 \%)$ presented with symptoms directly to our department. There were 8 women and 18 men with a mean age of 51.4 years \pm 14 (range 23 to 82 years). In our patient group twenty-four patients $(92.3 \%)$ had a mean number of $2.54 \pm 1.4$ (range 1-6) comorbidities. The most common comorbidities were diabetes, obesity, heart diseases, nicotine- and/or alcohol-abuse (Table 1). The mean body mass index (BMI) in our study group was $28.7 \pm 7.6$ (range 18 to 51.6). Six Patients $(23.1 \%)$ used corticoids because of chronic inflammatory bowel disease, Felty syndrome, mixed connective tissue disease or polyarthritis. Only two patients $(7.7 \%)$ had no relevant comorbidities.

The infection was localized in seven patients $(26.9 \%)$ at the perineum, in eight patients $(30.8 \%)$ at the extremities and eleven patients $(42.3 \%)$ had truncal involvement (Fig. 1). The port of entry of the infection could be identified in only thirteen patients (50 $\%)$. In seven cases of postoperative necrotizing fasciitis re-exploration of the wound established the diag-
Table 1. Spectrum of comorbidities in patients $(n=26)$ with necrotizing fasciitis

\begin{tabular}{lc}
\hline Comorbidity & No. of patients [\%] \\
\hline Diabetes mellitus & $12(46.2 \%)$ \\
Obesity & $8(30.8 \%)$ \\
Heart disease & $8(30.8 \%)$ \\
Alcohol abuse & $7(26.9 \%)$ \\
Smoking & $9(34.6 \%)$ \\
Steroid usage & $6(23.1 \%)$ \\
Asthma/COPD & $5(19.2 \%)$ \\
Chronic inflammatory bowel disease & $3(11.5 \%)$ \\
Cancer & $4(15.4 \%)$ \\
HIV & $1(3.8 \%)$ \\
Chronic renal insuficiency & $1(3.8 \%)$ \\
Autoimmune hemolytic anemia & $1(3.8 \%)$ \\
Peripheral vascular disease & $1(3.8 \%)$ \\
Felty syndrom & $1(3.8 \%)$ \\
Mixed tissue disease & $1(3.8 \%)$ \\
None & $2(7.7 \%)$ \\
\hline
\end{tabular}

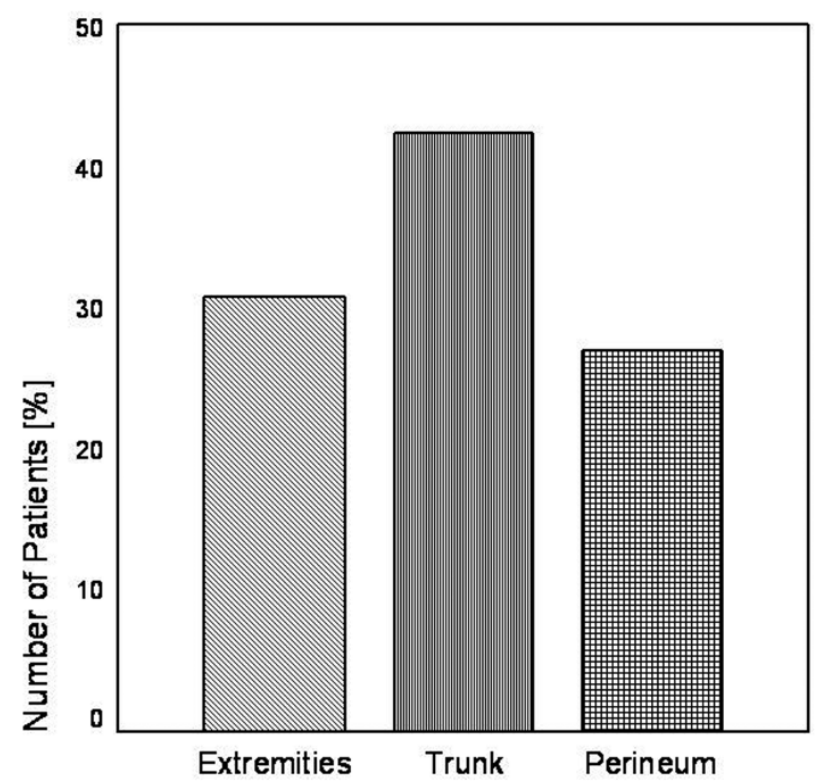

Fig. 1. Localization of necrotizing fasciitis.

nosis. Indications for initial surgery were toxic megacolon due to ulcerative colitis in one patient, antral resection due to gastric carcinoid tumour in one patient, intraabdominal adhesions in one patient, in two patients repair of incarcerated hernia and urological operations in another two patients. Rare entries included the site of drug injection (one patient, $3.8 \%$ ), dermatitis due to infection with scabies norvegica (one patient, $3.8 \%$ ) and a chronic non-healing wound after a preceding trauma or chronic venous insufficiency (three patients, $11.5 \%$ ).

The presenting symptoms and their relative frequencies are reported in Table 2. On admission six patients $(23.1 \%)$ were classified as ASA II, ten patients $(38.5 \%)$ as ASA III, nine patients $(34.6 \%)$ as ASA IV 
Table 2. Clinical and biochemical findings on admission in patients $(n=26)$ with necrotizing fasciitis.

\section{Clinical and Biochemical findings No. of patients [\%] on admission}

\begin{tabular}{lc}
\hline Swelling & $24(92.3 \%)$ \\
Erythema & $24(92.3 \%)$ \\
Pain & $21(80.8 \%)$ \\
Skin necrosis & $7(26.9 \%)$ \\
Bullae formation & $4(15.4 \%)$ \\
Putride Secretion & $4(15.4 \%)$ \\
Crepitus & $2(7.7 \%)$ \\
Sensory/motor deficiencies & $1(3.8 \%)$ \\
Compartment syndrom & $2(7.7 \%)$ \\
Tachycardia & $15(57.7 \%)$ \\
Hypotension & $13(50 \%)$ \\
Leucocytosis & $15(57.7 \%)$ \\
Leucopenia & $3(11.5 \%)$ \\
\hline
\end{tabular}

and one patient $(3.8 \%)$ as ASA V according to the criteria of the American Society of Anaesthesiologists [18]. The majority of patients consequently presented in a critical condition of severe systemic disease, thus requiring catecholamine treatment because of hemodynamic instability in thirteen patients $(50 \%)$. The mean total white blood cell count was $13874 / \mu \mathrm{l}$ \pm 8622.6 (range 2200 to 37260 ) and the mean $C$ - reactive protein level was $26.9 \mathrm{mg} / \mathrm{dl} \pm 13.5$ (range 0.9 to 58.1).

CT-scanning was performed in ten patients with necrotizing fasciitis $(38.5 \%)$, whereof diagnosis was correctly made in five cases $(50 \%)$ by two interpreting radiologists. A thickening of the fascial layer $(90 \%)$, edema of the adjacent muscle $(80 \%)$ and focal fluid collections (abscesses) (70\%) were detected more frequent in patients with necrotizing fasciitis (Fig. 2 A) than in CT scans performed for other soft tissue infections $(70 \%, 30 \%$ and $40 \%)$. Other CT morphological observations such as a stranding of the subcutaneous tissue (100\% in both groups) or soft tissue gas along fascial planes (50\% vs. $40 \%$ ) showed no obvious differences between both groups. CT scan therefore showed a sensitivity of only $50 \%$, a specificity of $80 \%$ and an accuracy of $71.4 \%$. There was no statistical significant correlation between CT-findings and other clinical or microbiological variables like type of infection or absence of anaerobes. In one patient with type II disease a biopsy was necessary in order to establish the diagnosis (Fig. 2 B).
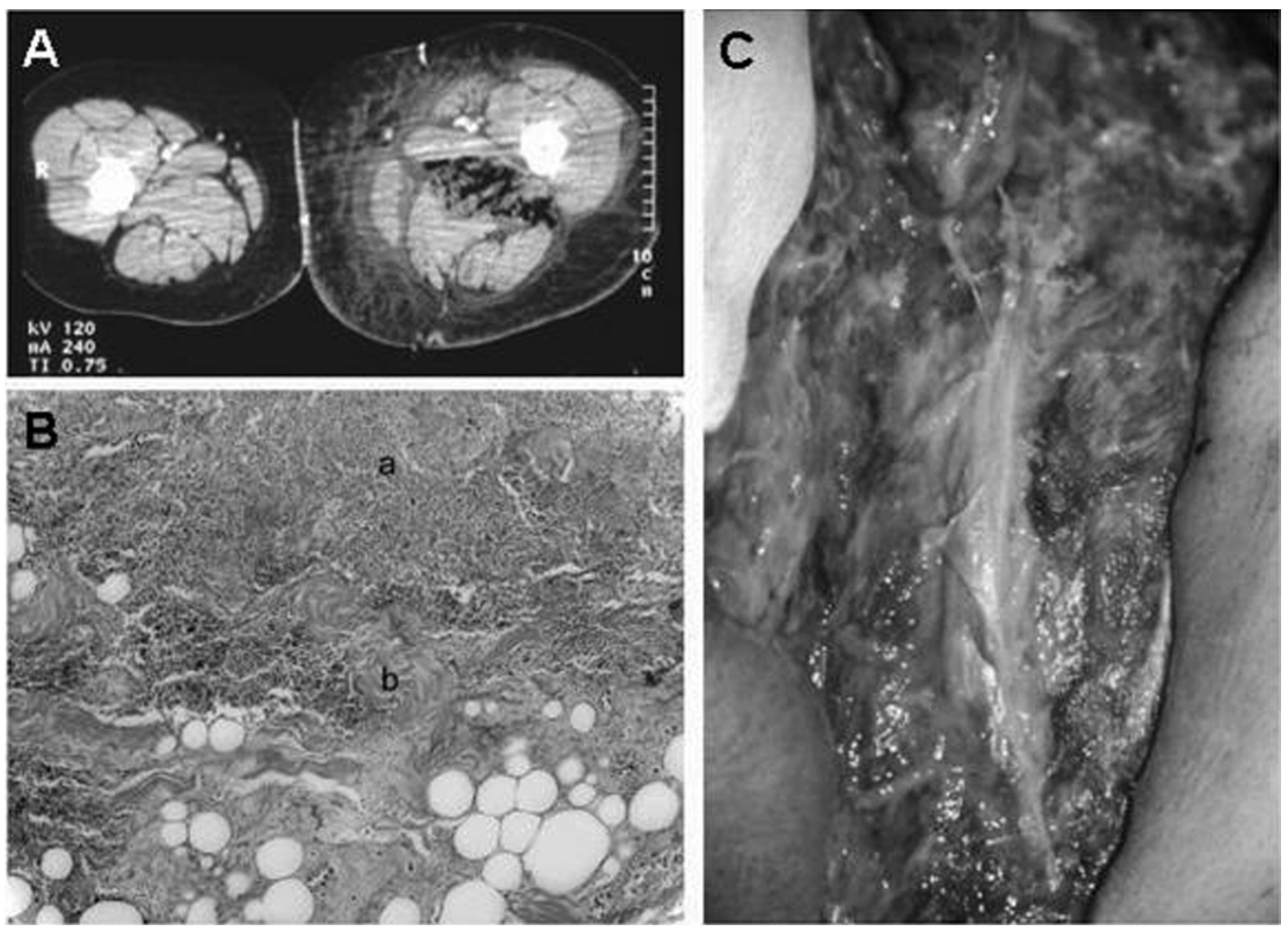

Fig. 2. Morphological aspects of necrotizing fasciitis. Typical aspects on computed tomography (CT) scan included a thickening of the fascial layer, stranding of the subcutaneous tissue as well as edema of the adjacent muscle and local gas collections. (B) Histological hallmarks of necrotizing fasciitis with subcutaneous (a) and fascial (b) necrosis. (C) Intraoperative typical appearance of necrotic fascial layer and surrounding inflammatory tissue. 


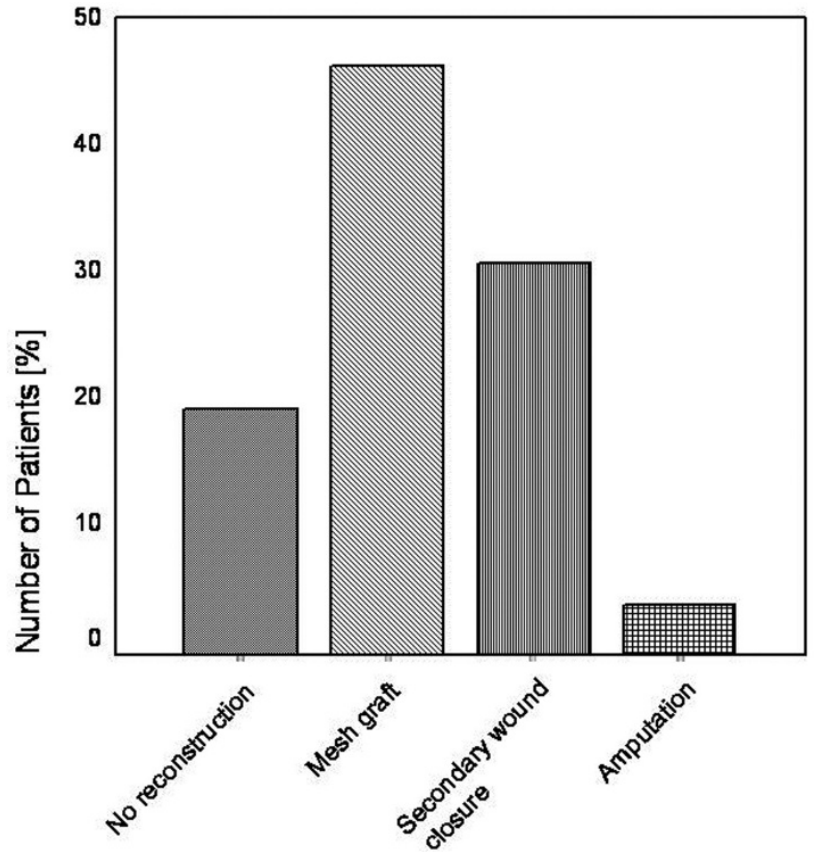

Fig. 3. Definitive reconstructions after successful treatment of necrotizing fasciitis.

An initial necrosectomy with debridement of necrotic tissue and fascia was performed in all patients until healthy, vascularized margins were reached (Fig. 2 C). Twenty-one patients $(80.8 \%$ ) underwent at least one revision because of progressing necrotic and inflammatory tissue (range 1 to 8), of which the first was necessary in two patients $(10 \%)$ on the subsequent day. Three patients with involvement of the perineum received a colostomy. The mean delay from onset of symptoms to operation was 3.6 days \pm 3.3 (range 0 to 14 days). Because of progressive infection after initial debridement an amputation below the knee was necessary in one patient for definitive treatment. A mean number of $3.7 \pm 2.1$ (range 1 to 10 ) operations were performed until complete resolution of the infection and reconstruction. Definitive reconstruction procedures included mesh graft coverage in twelve patients $(46.2 \%)$ or secondary wound closure in eight patients $(30.8 \%)$. No reconstruction was performed in five patients $(19.2 \%)$ due to a fatal outcome (Fig. 3).

Bacteriological culture results of tissue specimen or smears obtained at the first debridement identified in nine patients $(34.6 \%$ ) a single organism and in thirteen patients $(50 \%)$ multiple organisms. In four patients $(15.4 \%)$ no organism could be isolated. Thus in fourteen patients $(53.8 \%)$ a type I polymicrobial necrotizing fasciitis according to the classification by Giuliano et al. was present. As summarized in Table 3, isolates in these patients included non-group-A streptococci, staphylococci, enterobacteriaceae such as escherichia coli, klebsiella species, pseudomonas species and anaerobes. Eight infections (30.8\%) were type II infections according to the classification by Giuliano et al. [4] and were caused by group-A b haemolysing streptococci alone or in combination
Table 3. Microbiological isolates among patients $(\mathrm{n}=26)$ with necrotizing fasciitis.

\begin{tabular}{ll}
\hline Organism & Number [\%] \\
\hline Group-A Streptococcus & $8(30.8 \%)$ \\
Non-Group-A Streptococcus & $2(7.7 \%)$ \\
Enterococcus & $4(16 \%)$ \\
Escherichia coli & $6(23 \%)$ \\
Proteus & $1(3.8 \%)$ \\
Klebsiella & $1(3.8 \%)$ \\
Staphylococcus & $5(19.2 \%)$ \\
Anaerobes & $8(30.8 \%)$ \\
Unknown/no growth & $3(11.5 \%)$
\end{tabular}

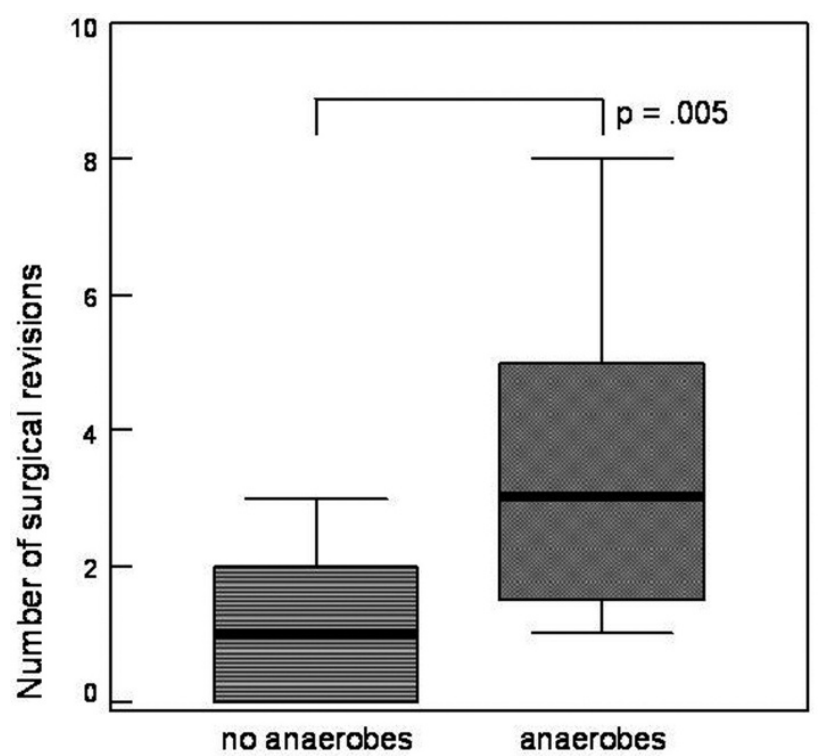

Fig. 4. Relationship between number of surgical revisions and existence of anerobic bacterial strains ( $p=0.005$; MannWhitney-test).

with staphylococci. Patients with positive anaerobic bacteriological cultures underwent significantly $(p=$ 0.005 ) more surgical procedures (median 3; quartile range 25\%-75\%: 1.25-5.5; interquartile range: 4.25 ) than patients without anaerobic involvement (median 1 ; quartile range $25 \%-75 \%: 0-1$; interquartile range: 1 ) (Fig. 4).

The mean length of stay was $48.1 \pm 25.5$ days (range 2 to 113$) .19$ patients $(73.1 \%$ ) were admitted to our intensive care unit with a mean ICU stay of $20.1 \pm$ 19.9 days (range 1 to 61 days). Out of this group twelve patients $(63.2 \%)$ required a mean of $20.3 \pm 16$ respirator days (range 1 to 61 days). Patients with severe systemic infection (ASA IV - V) had to be ventilated for a significantly ( $p=0.003$ ) longer period (median 16.5; quartile range 25\%-75\%: 3.25-26.75; interquartile range: 23.5$)$ than patients without any clinical signs of severe systemic inflammation (ASA II and III) (median 0: quartile range 25\%-75\%: 0-0; interquartile range: 0) (Fig. 5 A). Additionally ASA IV and $\mathrm{V}$ patients suffering from necrotizing fasciitis re- 

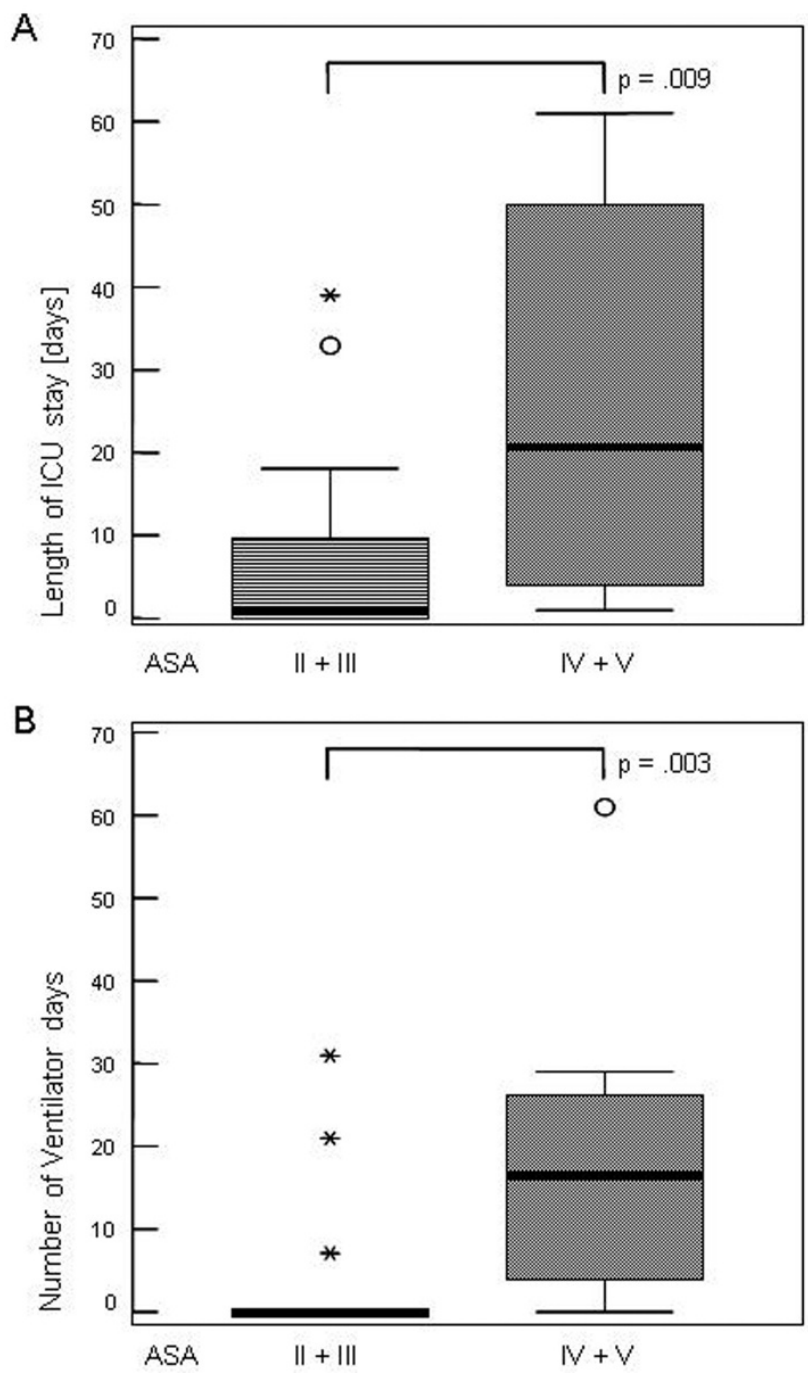

Fig. 5. Prognostic impact of the classification according the American Society of Anaesthesiologists (ASA) and course of disease. ASA IV and V patients had to be (A) ventilated for a longer period $(p=0.003)$ and $(\mathrm{B})$ required a longer intensive care unit $(\mathrm{ICU})$ stay $(p=0.009)$.

quired a significantly $(p=0.009)$ longer ICU stay (median 20.5; quartile range 25\%-75\%: 3.25-51; interquartile range: 47.75$)$ than patients classified to ASA II and III (median 1; quartile range 25\%-75\%: 0-9.75; interquartile range 9.75) (Fig. 5 B). Seven patients (26.9 $\%)$ suffered from acute renal failure, five of which required $(19.2 \%)$ hemofiltration or hemodialysis. Further organ dysfunctions involved in eleven patients $(42.3 \%)$ the lung and in six patients $(23.1 \%)$ the liver. The overall mortality was $19.2 \%(\mathrm{n}=5)$. All patients who died presented on admission with a severe systemic infection with life threatening organ failure and were classified as ASA IV or V patients. ASA IV or V patients had a mortality of $50 \%$. Survivors had a significantly lower ASA score on admission $(p=0.036)$ than non survivors (Fig. 6). There was no statistical significant correlation between the lengths of symptoms, comorbidities, white blood cell count, type of infection or areas involved to the mortality or ICU stay.

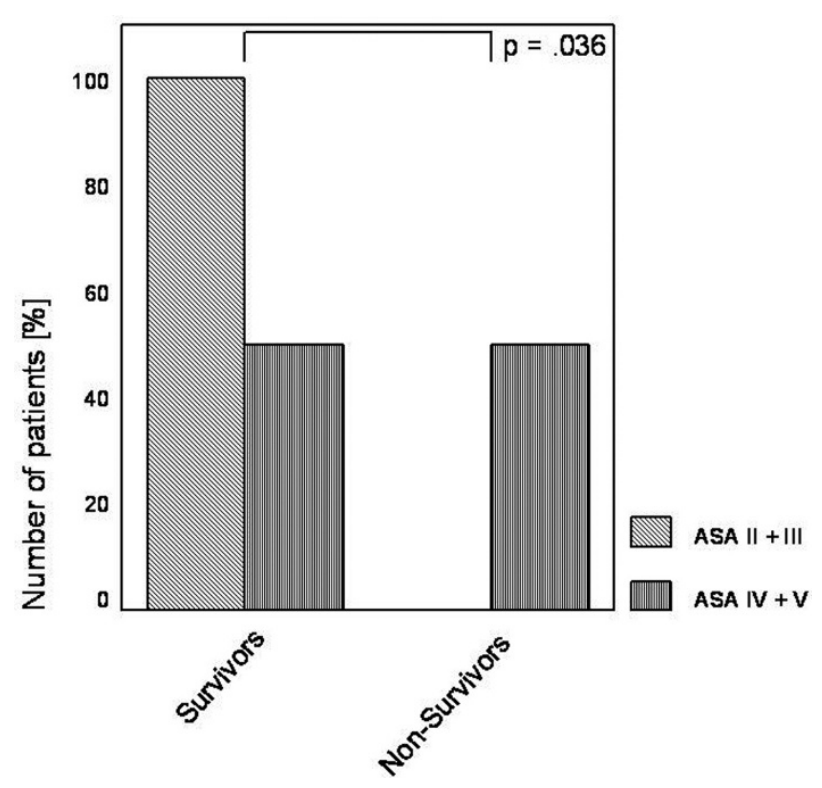

Fig. 6. Relationship between the classification according American Society of Anaesthesiologists (ASA) and mortality While none of the patients classified as ASA II-III died, mortality in patients with ASA IV-V was $50 \%$. $(p=0.036$; Mann-Whitney-test).

\section{Discussion}

Necrotizing fasciitis is a life threatening, rapidly progressing soft tissue infection with a high mortality up to $76 \%$. However, early diagnosis and extensive surgical debridement of all necrotic tissue has been demonstrated to improve survival $[7,8,19,20]$. Paucity of clinical findings in the early course of the infection makes a timely diagnosis difficult. Early signs of disease do not include skin necrosis, crepitus or dishwater pus, in particular in type II infections.

The therapy has to be initiated as early as possible, but radical skin debridement in patients who turn out not to suffer from necrotizing fasciitis has to be avoided. Therefore further diagnostic tools such as imaging procedures or histopathologic examination have to be used. Yen and colleagues [21] applied the criterion of diffuse thickening of the subcutaneous tissue accompanied by a fluid layer amounting more than four millimetres along the fascia in a prospective study using ultrasound techniques. They found a sensitivity of $88.2 \%$ and a specificity of $95.4 \%$. More frequently used, CT scan may recognize fasciitis by detecting diffuse enhancement and thickening of the superficial and deep fascia as well as soft tissue gas or fluid collections $[14,15]$. Consistent with previous reports typical diagnostic features at $\mathrm{CT}$ in our group were fascial thickening with enhancement and edema of the adjacent muscle, as well as fat stranding, fluid collections and gas tracking along fascial planes. CT scanning might help the surgeon to show the extension of an infectious process, but was in our group limited in its validity to distinguish between necrotizing fasciitis and other soft tissue infections. More suitable in distinguishing between necrotizing fasciitis and cellulites seems to be MR imaging with a reported sensitivity of 
$100 \%$ and a specificity of $86 \%$ performed in a group of seventeen patients consisting of eleven cases of necrotizing fasciitis and six cases of cellulites [16]. Thus, supporting that MR imaging rather than CT scanning should be preferred as diagnostic tool in necrotizing fasciitis. To establish the diagnosis of necrotizing fasciitis the correlation of clinical, imaging, and laboratory findings is mandatory. As formerly described, a frozen-section or rapid embedding biopsy of suspicious lesions is useful for early definitive diagnosis and can therefore reduce mortality significantly $[22,23]$.

Our operative strategy is aggressive debridement with complete removal of all necrotic areas until healthy tissue is exposed. Skin flaps are moderately trimmed and separated from the underlying tissue by surgical towels. Necrotic areas are resected. A daily examination of the wound must be performed in order to asses the local conditions and to exclude a progression of infection and necrosis.

Most of our patients presented on admission with typical symptoms of early necrotizing fasciitis such as swelling, erythema, pain out of proportion to physical examination and fever. Signs of a more progressive stage of the disease such as skin necrosis, purulent secretion, hemorrhagic bullae formation, crepitus and signs of a compartment syndrome as well as sensory and motor deficiencies were observed only in a minority of patients. Histopathologically, necrosis of the superficial fascia combined with angiothrombosis and suppuration are characteristic $[11,12]$. Thereby subcutaneous fat necrosis mostly without major changes of the epidermis occurs as well as inflammation of the dermis and subcutaneous fat with infiltrating leucocytes. Bakleh and associates [13] concluded from a group of 63 cases with necrotizing fasciitis that histopathological findings and clinical course may correlate and established a model of three stages.

In our study the most common infection was a type I-polymicrobial infection with a prevalence of $53.8 \%$. In $30.8 \%$ of our patients with type I infections, cultures grew also anaerobes. Patients with positive anaerobic cultures needed more surgical revisions, suggesting that especially these patients might profit from a hyperbaric oxygen therapy (HBO) in the adjuvant therapy of necrotizing fasciitis. A reduction of mortality and a decreased need of debridements were reported [24-27]. In particular, patients suffering from infections with anaerobes may benefit from HBO therapy because of the direct toxic effect of increased free radicals through increased oxygenation in the hypoxic tissue area [28].

The classification of physical status according to the American Society of Anaesthesiologists [18] correlates with perioperative mortality or postoperative outcome $[29,30]$. So far, the prognostic value for patients suffering from necrotizing fasciitis had not been shown. We found a correlation between ASA status and days on the ICU, days on the respirator, and survival.

Necrotizing fasciitis remains a major challenge for several reasons. While it is of utmost importance to diagnose the disease early in its course, the signs may be very unspecific and less severe conditions such as cellulitis or may be considered. Once the suspicion of necrotizing fasciitis is raised immediate action is required. The diagnosis and extent have to be established. Resection of all affected fascia may require the resection of large segments of viable skin and subcutaneous tissue. The problems are particularly striking in type II necrotizing fasciitis, where typical foulsmelling dishwater pus is missing.

In order to overcome these difficulties, we instituted a "necrotizing fasciitis alertness" team, including an experienced staff member, which is supposed to see all patients who are under suspicion immediately after admission. If immediate diagnosis cannot be established, diagnostic procedures like MR- or CT-imaging and fascial biopsy are initiated.

In summary, the need for early diagnosis and aggressive therapy has been stressed before in the literature $[7,8,19,20]$. We confirm this approach. Our diagnostics consisted of three steps: examination by a surgical infectious disease specialist, CT-or MR-scan and, if necessary, a biopsy, processed by rapid embedding. This allowed us to submit all patients to definitive therapy within 24 hours. In one case the diagnosis was substantiated by a biopsy prior to major surgery, in 10 cases the nature and extent of the disease was determined by CT-scan, showing a limited diagnostic validity. If anaerobes are isolated in necrotizing fasciitis an early and aggressive second look is necessary. At the same time, however, the basis of timely therapy is a high level of suspicion with no diagnostic tool being superior to clinical judgement.

\section{REFERENCES}

1. Wilson B. Necrotizing fasciitis. Am Surg. 1952 Apr;18(4):416-31.

2. Singh G, Sinha SK, Adhikary S, Babu KS, Ray P, Khanna SK. Necrotising infections of soft tissues-a clinical profile. Eur J Surg. 2002;168(6):366-71.

3. Green RJ, Dafoe DC, Raffin TA. Necrotizing fasciitis. Chest. 1996 Jul;110(1):219-29.

4. Giuliano A, Lewis F Jr, Hadley K, Blaisdell FW. Bacteriology of necrotizing fasciitis. Am J Surg. 1977 Jul;134(1):52-7.

5. Chen JL, Fullerton KE, Flynn NM. Necrotizing fasciitis associated with injection drug use. Clin Infect Dis. 2001 Jul 1;33(1):6-15.

6. Roujeau JC. Necrotizing fasciitis. Clinical criteria and risk factors. Ann Dermatol Venereol. 2001 Mar;128(3 Pt 2):376-81. Review.

7. McHenry CR, Piotrowski JJ, Petrinic D, Malangoni MA. Determinants of mortality for necrotizing soft-tissue infections. Ann Surg. 1995 May;221(5):558-63.

8. Wong CH, Chang HC, Pasupathy S, Khin LW, Tan JL, Low CO. Necrotizing fasciitis: clinical presentation, microbiology, and determinants of mortality. J Bone Joint Surg Am. 2003 Aug;85-A(8):1454-60.

9. Elliott DC, Kufera JA, Myers RA. Necrotizing soft tissue infections. Risk factors for mortality and strategies for management. Ann Surg. 1996 Nov;224(5):672-83.

10. Wong CH, Wang YS. The diagnosis of necrotizing fasciitis.Curr Opin Infect Dis. 2005 Apr;18(2):101-6. Review.

11. Umbert IJ, Winkelmann RK, Oliver GF, Peters MS. Necrotizing fasciitis: a clinical, microbiologic and histopathologic study of 14 patients. J Am Acad Dermatol. 1989 May;20(5 Pt 1):774-81. 
12. Barker FG, Leppard BJ, Seal DV. Streptococcal necrotising fasciitis: comparison between histological and clinical features. J Clin Pathol. 1987 Mar;40(3):335-41.

13. Bakleh M, Wold LE, Mandrekar JN, Harmsen WS, Dimashkieh HH, Baddour LM. Correlation of histopathologic findings with clinical outcome in necrotizing fasciitis. Clin Infect Dis. 2005 Feb 1;40(3):410-4.

14. Wysoki MG, Santora TA, Shah RM, Friedman, AC. Necrotizing fasciitis: CT Characteristics. Radiology. 1997 Jun;203(3):859-63.

15. Fugitt JB, Puckett ML, Quigley MM, Kerr SM. Necrotizing fasciitis. Radiographics. 2004 Sep-Oct;24(5):1472-6.

16. Schmid MR, Kossmann T, Duewell S. Differentiation of necrotizing fasciitis and cellulitis using MR imaging. AJR Am J Roentgenol. 1998 Mar;170(3):615-20.

17. Brothers TE, Tagge DU, Stutley JE, Conway WF, Del Schutte H Jr, Byrne TK. Magnetic resonance imaging differentiates between necrotizing and non-necrotizing fasciitis of the lower extremity. J Am Coll Surg. 1998 Oct;187(4):416-21.

18. Owens WD, Felts JA, Spitznagel EL Jr. ASA physical status classifications: a study of consistency of ratings. Anesthesiology. 1978 Oct;49(4):239-43.

19. Voros D, Pissiotis C, Georgantas D, Katsaragakis S, Antoniou S, Papadimitriou J. Role of early and extensive surgery in the treatment of severe necrotizing soft tissue infection. Br J Surg. 1993 Sep;80(9):1190-1.

20. Ward RG, Walsh MS. Necrotizing fasciitis: 10 years `experience in a district general hospital. Br J Surg. 1991 Apr;78(4):488-9.

21. Yen ZS, Wang HP, Ma HM, Chen SC, Chen WJ. Ultrasonographic screening of clinically-suspected necrotizing fasciitis. Acad Emerg Med. 2002 Dec;9(12):1448-51.

22. Majeski J, Majeski E. Necrotizing fasciitis: improved survival with early recognition by tissue biopsy and aggressive surgical treatment. South Med J. 1997 Nov;90(11):1065-8.

23. Stamenkovic I, Lew PD. Early recognition of potentiallyy fatal necrotizing fasciitis: the use of frozen section biopsy. N Engl J Med. 1984 Jun 28;310(26):1689-93.
24. Riseman JA, Zamboni WA, Curtis A, Graham DR, Konrad HR, Ross DS. Hyperbaric oxygen therapy for necrotizing fasciitis reduces mortality and the need for debridements. Surgery. 1990 Nov;108(5):847-50.

25. Brown DR, Davis NL, Lepawsky M, Cunningham J, Kortbeek J. A multicenter review of the treatment of major truncal necrotizing infections with and without hyperbaric oxygen therapy. Am J Surg. 1994 May;167(5):485-9.

26. Sugihara A, Watanabe H, Oohashi M, Kato N, Murakami H, Tsukazaki S, Fujikawa K. The effect of hyperbaric oxygen therapy on the bout of treatment for soft tissue infections. J Infect. 2004 May;48(4):330-3.

27. Wilkinson D, Doolette D. Hyperbaric oxygen treatment and survival from necrotizing soft tissue infection. Arch Surg. 2004 Dec;139(12):1339-45.

28. McCord JM, Keele B-B, Fridovich I. An enzyme-based theory of obligate anaerobiosis: the physiological function of superoxide dismutase. Proc Natl Acad Sci U S A. 1971 May;68(5):1024-7.

29. Wolters U, Wolf T, Stützer H, Schröder T. ASA classification and perioperative variables as predictors of postoperative outcome. Br J Anaesth. 1996 Aug;77(2):217-22.

30. Klotz HP, Candinas D, Platz A, Horvàth A, Dindo D, Schlumpf R, Largiadèr F. Preoperative risk assessment in elective general surgery. Br J Surg. 1996 Dec;83(12):178891.

Received: June 17, 2008 / Accepted: July 22, 2008

Address of correspondence:

Dr. Andreas Krieg

Department of General Surgery

Heinrich Heine University

Moorenstr. 5

40225 Duesseldorf

Germany

Phone: +492118117351

Fax: $\quad+492118117359$

E-mail: andreas.krieg@med.uni-duesseldorf.de 